Research Article

\title{
Synthesis and Characterization of New Epoxy/titanium Dioxide Nanocomposite
}

\author{
Sabah Mohammed Mlkat al Mutoki ${ }^{1}$, Baydaa Abdul-Hassan Khalaf Al-Ghzawi ${ }^{2}$, Ali Abdulabbas \\ Abdullah $^{3}$, Ammar I.R. AlAmmar ${ }^{4}$, Emad A. Jaffar Al-Mulla ${ }^{5}$ \\ ${ }^{1}$ Electrical Department, Al Furat Al Awsat University, Technical Institute of Samawa, Samawa, Iraq \\ ${ }^{2}$ Mechanical Department, Al Furat Al Awsat University, Technical Institute of Samawa, Samawa, Iraq \\ ${ }^{3}$ Electrical Department, Al Furat Al Awsat University, Al-Najaf Engineering Technical College, An-Najaf, Iraq \\ ${ }^{4}$ Oil Products Distribution company, Ministry of Oil, Baghdad, Iraq \\ ${ }^{5}$ Department of Chemistry, Faculty of Science, University of Kufa, P.O. Box 21, An-Najaf 54001, Iraq \\ Corresponding author: E-mail: asabah_sh2003@yahoo.com; imad.almulla@uokufa.edu.iq
}

Received: Sept. 24, 2015; Accepted: Oct. 12, 2015; Published: Oct. 23, 2015.

Citation: Sabah Mohammed Mlkat al Mutoki, Baydaa Abdul-Hassan Khalaf Al-Ghzawi, Ali Abdulabbas Abdullah , Ammar I.R. AlAmmar and Emad A. Jaffar Al-Mulla. Synthesis and Characterization of New Epoxy/titanium Dioxide Nanocomposite. Nano Biomed. Eng. 2015, 7(4), I35-I38. DOI: 10.510I/nbe.v7i4.pI35-138.

\begin{abstract}
Titanium dioxide nano filler $\left(\mathrm{TiO}_{2}\right)$ with $(10 \mathrm{~nm})$ particle size, and $(0.5 \mathrm{wt} \%)$ was used as a dopant to epoxy type (SR8100), polymer matrix nanocomposite (PMNC) was prepared by hot vibration dispersion, and tested using FTIR, and UV spectra. It has been found that transmission of (PMNC) largely enhanced, and absorption of UV radiation reaches up to $(52 \%)$ at $(500 \mathrm{~nm}),(50 \%)$ at $(1000$ $\mathrm{nm})$, and never drop to zero.
\end{abstract}

Keywords: Nano filler; PMNCs; Hot vibration dispersion

\section{Introduction}

Nanocomposites are composites in which at least one of the phases shows dimensions in the nanometre range [1-5]. Conducting polymer-based composites are novel materials with less than a decade of history. It is believed that the total control of the whole conducting polymer-based composite system and the optimization of their physical properties [6]. Nanosized fillers have been introduced in a wide spectrum of applications ranging from providing photo-catalyst activation and conductivity $[7,8]$ to improving melt processability [9-12] and moisture barrier properties. The special properties of nanoparticles are due to their size and high relative surface area to volume ratio. The optical clarity of a spherical nanosize particle is better than that of its equivalent conventional-size filler, because the diameter is smaller than the wavelengths of light. As a nanosize filler particle has a larger specific surface area than its analogous traditional-size filler particle, it interacts more with its surroundings. Thermodynamic stability of the polymer nanocomposite, which is due to the large interfacial phase between the matrix and the nanoparticle [13,14], yields the physical properties of the composite. Polymer-based electronics have the capability of being used to make cheap devices [15]. Numerous efforts are being taken to improve the efficiency of the PMNCs electronics. In general a higher density of the nanoparticles is advantageous. Control of the band edge of the particles is also very 
important factor controlling the efficiency of such items. Polymer semiconductor nanocomposites offer the promise of a new generation of hybrid materials with numerous possibilities of applications such as in optical displays, catalysis, photovoltaics, gas sensors, electrical devices, mechanics, photoconductors and superconductor devices [16-18]. metal and ceramic reinforcements offer striking routes to certain unique magnetic, electronic, optical or catalytic properties coming from inorganic nanoparticles, which add to other polymer properties such as processibility and film forming capability. Using this approach, polymers can be improved while keeping their lightweight and ductile nature [19-21]. Aim of this work was to produce a new PMNC material made from (SR8100) epoxy, and nano $\left(\mathrm{TiO}_{2}\right)$ filler, and detect its properties.

\section{Materials and Methods}

Epoxy type (SR8100) containing resin and hardener from (SICOMIN, USA), and $(99.9 \%) \mathrm{TiO}_{2}$ from (HORIBA, Germany) with particle size distribution as illustrated in Fig. 1 was used as a matrix and filler. Polymer matrix discs were prepared using mould with $(2 \mathrm{~cm})$ diameter, and $(1 \mathrm{~cm})$ height, resin and hardener was mixed by $(1: 3 \mathrm{wt} \%)$, stirred by a magnetic stirrer for (5 min), then it was purred into the mould leaving for $(24 \mathrm{hrs})$. After solidification we put polymer discs in $(2 \times 1 \mathrm{~cm})$ cylindrical mould with a moving base, on the base $(0.5 \mathrm{gm})$ of $\mathrm{TiO}_{2}$ nano powder was spread, the mould then was heated up to $\left(120^{\circ} \mathrm{C}\right)$ and vibrate at $(60 \mathrm{rpm})$ for $(1 \mathrm{hr})$ to disperse $\mathrm{TiO}_{2}$ nano particles in epoxy matrix, then it was left to cool down to room temperature. Specimen was tested by UV, and FTIR to detect their properties.

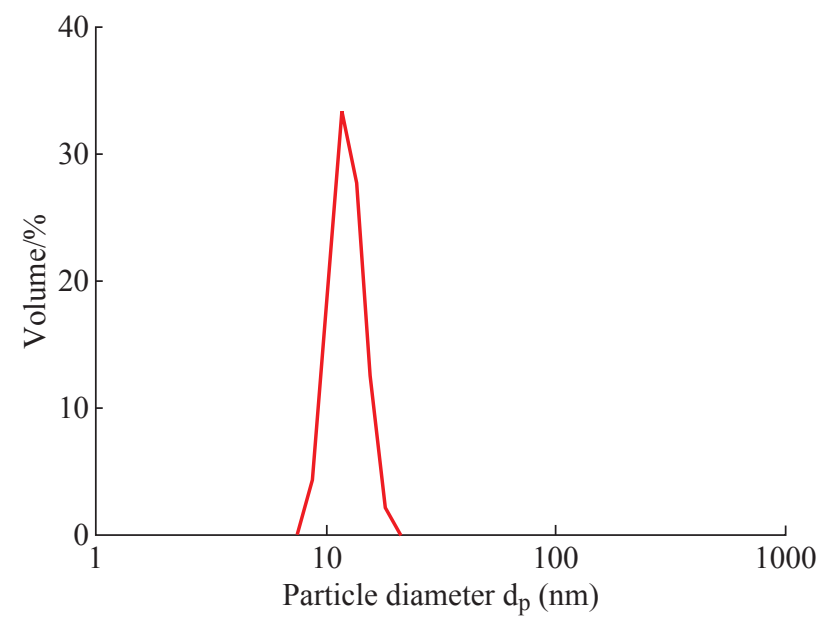

Fig. 1 Particle size distribution of $\mathrm{nTiO}_{2}$.

\section{Results and Discussion}

Optical properties to achieve transparency, scattering must be minimized, which means that the nano particles should be as small as possible while the index of refraction should remain as similar as possible to the matrix, excellent use of nano particles in (PMNCs) is in controlling the index of refraction which can be achieved by tailoring the volume fraction of nano particles.

Figures 2-4 illustrate that UV absorption of epoxy type (SR 8100), nano $\mathrm{TiO}_{2}$, and PMNC of epoxy/nano $\mathrm{TiO}_{2}$, respectively. It is easily to notice that for both polymer matrix, and nano $\mathrm{TiO}_{2}$ filler absorption ends at wave length of (500 nm), and gradually approaches to aero at higher wave lengths, while for the PMNC specimen we notice that absorption reach its maximum value at $(500 \mathrm{~nm})$ wave length which is $(52 \%)$, and this is a large enhancement, absorption continue all over wave lengths up to $(1100 \mathrm{~nm})$ where it is greater than (50\%), while at both polymer matrix, and nano filler it reach to zero at $(500 \mathrm{~nm})$, and $(400 \mathrm{~nm})$ respectively.

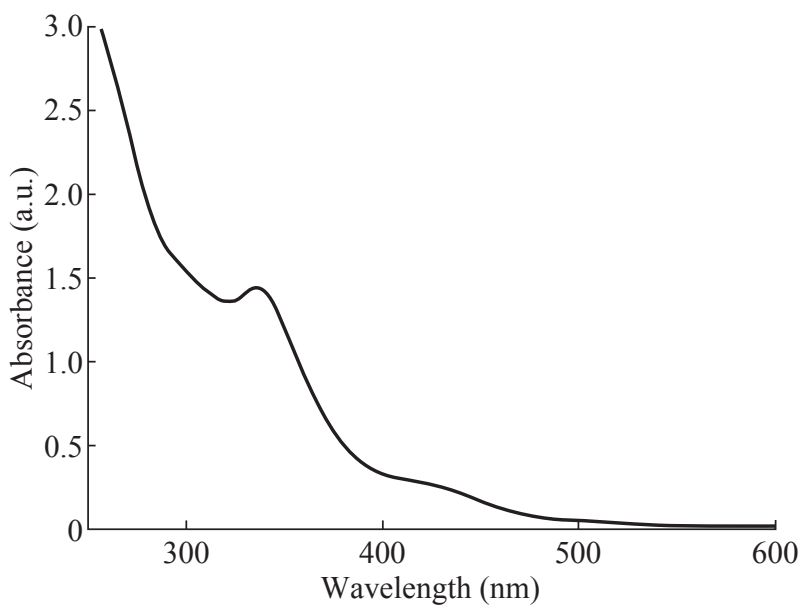

Fig. 2 UV of $\mathrm{TiO}_{2}$.

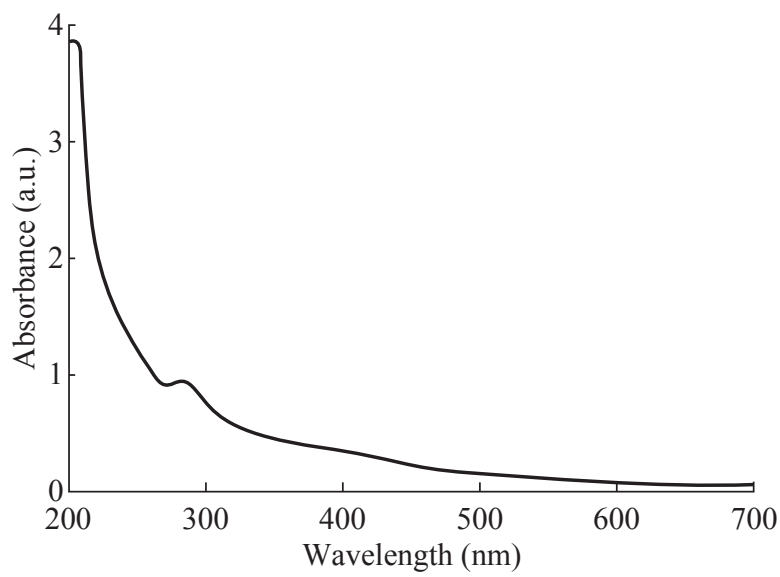

Fig. 3 UV of Epoxy. 


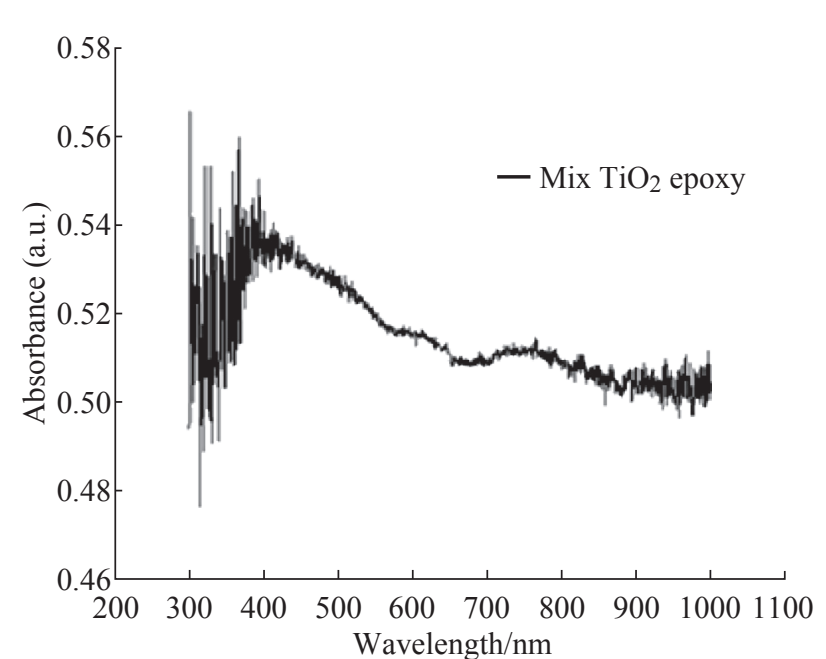

Fig. 4 UV of Epoxy/nano $\mathrm{TiO}_{2} \mathrm{PMNC}$

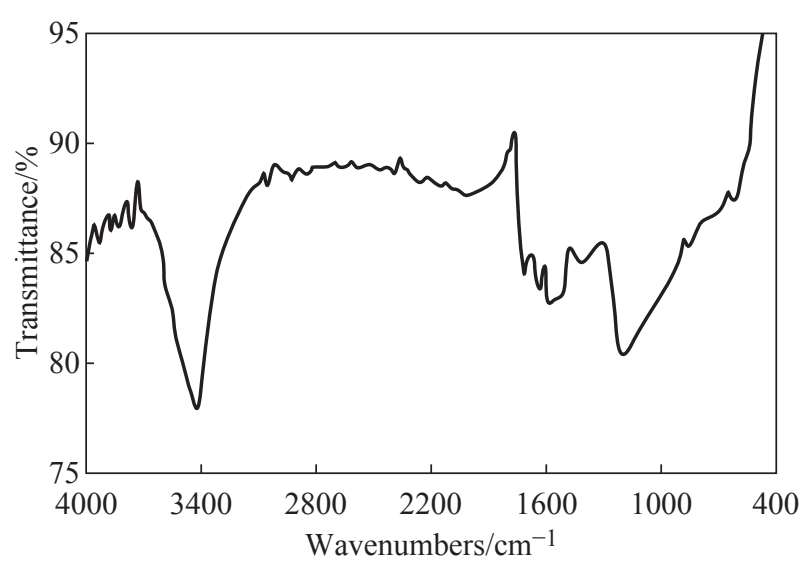

Fig. 5 FTIR of $\mathrm{TiO}_{2}$.
This high absorption rate and its continuity even at higher wave lengths is due to the improvement in PMNC, and this is came from the transition from bulk to surface state.

Figures 5-7 illustrate FTIR of of $\mathrm{TiO}_{2}$, Epoxy, and Epoxy/nano $\mathrm{TiO}_{2}$ composite, respectively. We notice that possibility of transmission transfer for the PMNC is too high and contineous, which exactly agree with the results of UV results. PMNC also produce some similar peaks to polymer matrix such as peaks at $(1427.32,1635.64)$ which refers to phases where epoxy is the dominant, while peaks at $(3587.60$, $3525.88,3464.15)$ are the places where $\mathrm{TiO}_{2}$ nano filler concentrate.

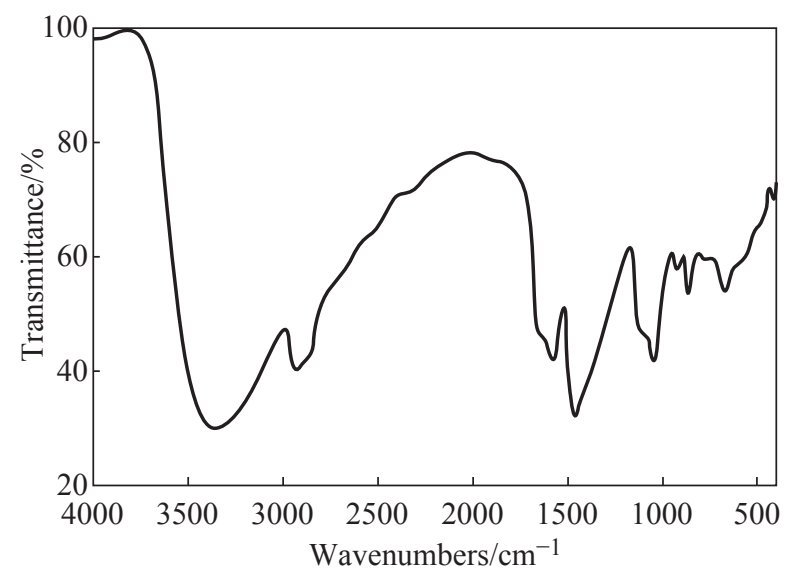

Fig. 6 FTIR of Epoxy.

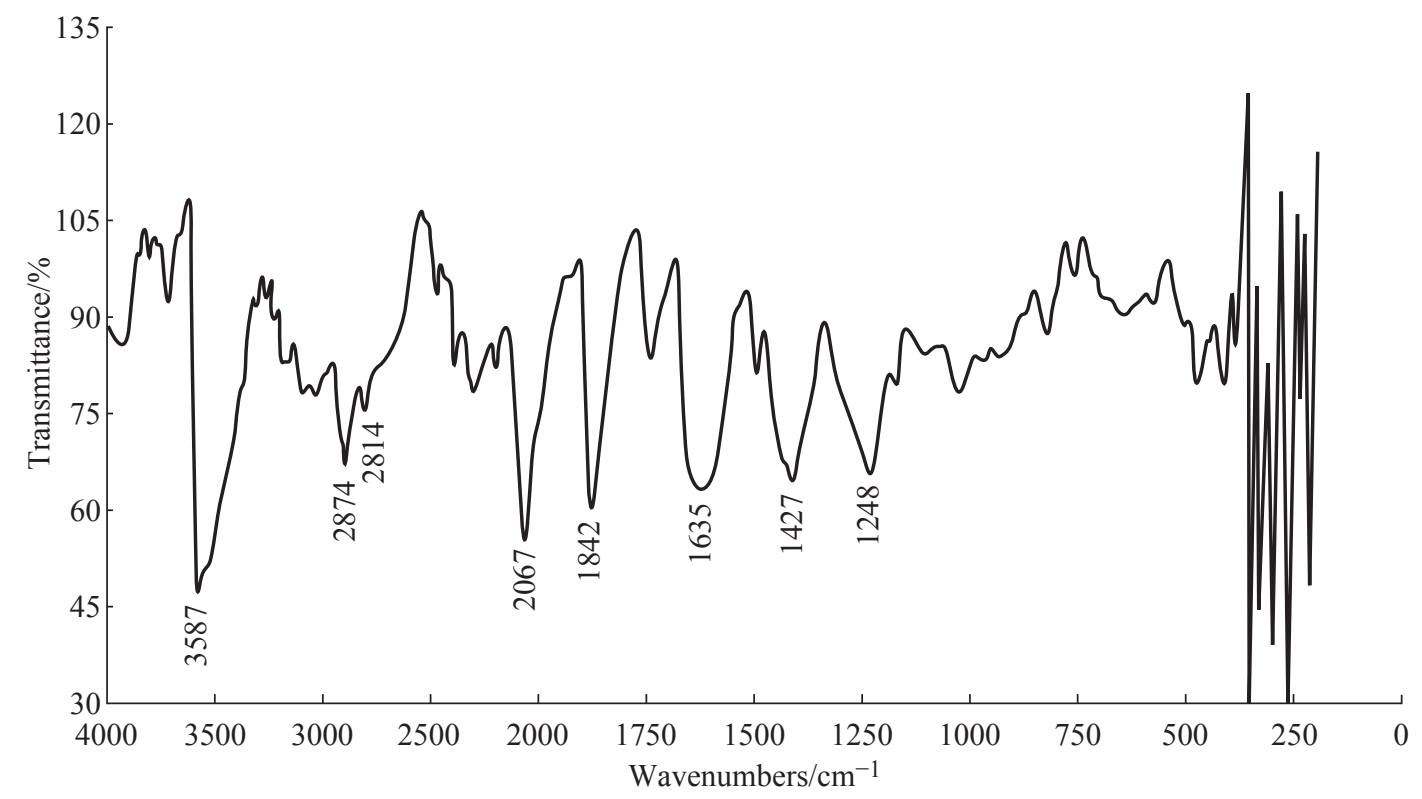

Fig. 7 FTIR of SR8100/nTiO $\mathrm{PMNC}$

\section{References}

[1] E. Thostenson, C. Li, T. Chou. Review Nanocomposites in Context. J. Comp. Sci. Tech. 2006, 65: 491-516.

[2] K. Friedrich. S. Fakirov, Z. Zhang. Titanium dioxide nanocomposites. Polym. Comp. 2005: 21-18.

[3] O.O. Christopher, M. Lerner, Nanocomposites and 
Intercalation Compound. Encyclo. Phy. Sci. Tech. 2005, 10, 3rd edn. Elsevier.

[4] S.K. Mazumder. Nano Composites Manufacturing, Materials, Product and Process Engineering, CRC Tayl. Fran. 2012, ISBN 0-8493-0585-3.

[5] K. Shameli. A.M. Ahmad. P. Shabanzadeh. Effect of Curcuma longa tuber powder extract on size of silver nanoparticles prepared by green method. Res. Chem. Intermed., 2014, 40: 1313-1325.

[6] E.A.J. Al-Mulla. A new biopolymer-based polycaprolactone/starch modified clay nanocomposite. Cell. Chem. Tech., 2014, 48(5-6): 515-520.

[7] K.W.S. Al-Janabi. Extraction of cobalt(II) from aqueous solution by N,N'-carbonyl difatty amides. Chin. Chem. Lett., 2011, 22(4): 69-72.

[8] Illyas Md Isa, Siti Nur Athirah Dahlan, Norhayati Hashim, Mustaffa Ahmad, Sazelli A. Ghani, Electrochemical Sensor for Cobalt(II) by Modified Carbon Paste Electrode with Zn/Al-2(3-Chlorophenoxy)Propionate Nanocomposite, Int. J. Electrochem. Sci., 7 (2012): $7797-$ 7808 .

[9] Svetlana Lichušina, Ala Chodosovskaja, Algis Selskis, Konstantinas Leinartas, Povilas Miečinskas, Eimutis Juzeliūnas, Pseudocapacitive behaviour of cobalt oxide films on nano-fibre and magnetron-sputtered substrates, chemija. 2008, 19. 3-4: 7-15.

[10] K. Shameli. A.M. Ahmad. Antibacterial effect of silver nanoparticles on talc composites. Res. Chem. Intermed., 2015, 41(1): 251-263.

[11] H.H. Balla, S. Abdullah, Effect of Reynolds number on heat transfer and flow for multi-oxide nanofluids using numerical simulation. Res. Chem. Intermed., 2013, 39(5): 2197-2210.

[12] W.H. Hoidy, M.B. Ahmad, Chemical synthesis and characterization of palm oil-based difatty Acyl thiourea. $J$. Oleo Sci., 2010, 59(5): 229-233.

[13] N.A. Ibrahim, M.Z.A. Rahman Difatty acyl urea from corn oil: Synthesis and characterization. J. Oleo Sci.,
2010, 59(3): 157-160.

[14] W.M. Yunus, N.A.B. Ibrahim, M.Z.A. Rahman. Enzymatic synthesis of palm olein-based fatty thiohydroxamic acids. J. Oleo Sci., 2010, 59(11): 569-573.

[15] W.M. Yunus, N.A.B. Ibrahim, M.Z.A. Rahman. Enzymatic synthesis of fatty amides from palm olein. $J$. Oleo Sci., 2010, 59(2): 59-64.

[16] A.A. Abdullah, S.A. Aowda, Electrochemical studies of copper fatty amides complex in organic medium. Res. Chem. Intermed., 2013, 39: 2817-2823.

[17] W.M.Z. Yunus, N.A.B. Ibrahim, M.Z.A. Rahman. Epoxidized palm oil plasticized polylactic acid/fatty nitrogen compound modified clay nanocomposites: Preparation and characterization. Polym Polym Comp., 2010, 18: 451-459.

[18] MM. Radhi, E.A.J. Al-Mulla, Application study of grafted polymer electrode in manganese ions during cyclic voltammetry. Rendiconti Lincei Scienze Fisiche E Naturali. 2014, 25: 209-213.

[19] F.A. Shemmari, A.A. RabaH. A comparative study of different surfactants for natural rubber clay nanocomposite preparation. Rendiconti Lincei Scienze Fisiche E Naturali, 2014, 25: 409-413.

[20] E.A.J. Al-Mulla. Lipase-catalyzed synthesis of fattythioic acids from palm oil. J. Oleo Sci., 2011, 60: 41-45.

[21] I.A. Mohammed, N.K. Kadar, M. Ibrahim. Structureproperty studies of thermoplastic and thermosetting polyurethanes using palm and soya oils-based polyols. $J$. Oleo Sci., 2013, 62 (12): 1059-1072.

Copyright $\subset 2015$ Sabah Mohammed Mlkat al Mutoki, Baydaa Abdul-Hassan Khalaf Al-Ghzawi, Ali Abdulabbas Abdullah, Ammar I.R. AlAmmar and Emad A. Jaffar Al-Mulla. This is an open-access article distributed under the terms of the Creative Commons Attribution License, which permits unrestricted use, distribution, and reproduction in any medium, provided the original author and source are credited. 